IZA DP No. 1314

Key Elasticities in J ob Search Theory:

International Evidence

\author{
J ohn T. Addison \\ Mário Centeno \\ Pedro Portugal \\ September 2004
}




\title{
Key Elasticities in Job Search Theory: International Evidence
}

\author{
John T. Addison \\ University of South Carolina \\ and IZA Bonn
}

Mário Centeno

Banco de Portugal

and Universidade Técnica de Lisboa

Pedro Portugal

Banco de Portugal

and Universidade Nova de Lisboa

\section{Discussion Paper No. 1314 \\ September 2004}

\author{
IZA \\ P.O. Box 7240 \\ 53072 Bonn \\ Germany \\ Phone: +49-228-3894-0 \\ Fax: +49-228-3894-180 \\ Email: iza@iza.org
}

Any opinions expressed here are those of the author(s) and not those of the institute. Research disseminated by IZA may include views on policy, but the institute itself takes no institutional policy positions.

The Institute for the Study of Labor (IZA) in Bonn is a local and virtual international research center and a place of communication between science, politics and business. IZA is an independent nonprofit company supported by Deutsche Post World Net. The center is associated with the University of Bonn and offers a stimulating research environment through its research networks, research support, and visitors and doctoral programs. IZA engages in (i) original and internationally competitive research in all fields of labor economics, (ii) development of policy concepts, and (iii) dissemination of research results and concepts to the interested public.

IZA Discussion Papers often represent preliminary work and are circulated to encourage discussion. Citation of such a paper should account for its provisional character. A revised version may be available directly from the author. 
IZA Discussion Paper No. 1314

September 2004

\section{ABSTRACT}

\section{Key Elasticities in Job Search Theory: International Evidence}

This paper exploits the informational value of search theory, after Lancaster and Chesher (1983), in conjunction with survey data on the unemployed to calculate key reservation wage and duration elasticities for most EU-15 nations.

JEL Classification: J64, J65

Keywords: reservation wages, probability of reemployment, accepted wages, unemployment benefits, Pareto wage offer distribution

Corresponding author:

John T. Addison

Department of Economics

Moore School of Business

University of South Carolina

1705 College Street

Columbia, SC 29208

USA

Email: ecceaddi@moore.sc.edu 


\section{Introduction}

The present treatment calculates four key elasticities in job search theory that are of importance for policy, using data from a unique international dataset containing information on individuals' reservation wages, unemployment benefits, and accepted wages. Specifically, we follow Lancaster and Chesher (1983) in providing estimates of the elasticity of the reservation wage with respect to the level of unemployment benefits, the elasticity of reservation wages with respect to the rate of job offers, the elasticity of unemployment duration with respect to the level of unemployment benefits, and the elasticity of unemployment duration with respect to the rate of job offers.

For the stationary optimal search model, Lancaster and Chesher show that these elasticities can be deduced by differentiating partially the optimality condition (for the reservation wage, $\xi$ ) with respect to the level of unemployment benefits, $b$, the job offer arrival rate, $\lambda$, and the hazard function, $\theta$, with respect to $\lambda$ and $\xi$. Writing the conditional expected wage as $x$, they obtain the following solution formulae for the elasticity of the reservation wage with respect to the level of unemployment benefits $\left(\eta_{\xi, b}\right)$ and the elasticity of reservation wages with respect to the rate of job offers $\left(\eta_{\xi, \lambda}\right)$, as follows:

$$
\eta_{\xi, b}=\frac{\partial \log \xi}{\partial \log b}=\frac{b}{\xi} \frac{x-\xi}{x-b},
$$

and

$$
\eta_{\xi, \lambda}=\frac{\partial \log \xi}{\partial \log \lambda}=\frac{\xi-b}{\xi} \frac{x-\xi}{x-b} .
$$

To obtain the solutions for the two remaining elasticities, however, some assumption has to be made concerning the hazard function of the offer distribution at the selected reservation wage, or $\frac{f(\xi)}{\bar{F}(\xi)}$. The authors assume that the portion of the wage offer distribution exceeding the benefit level follows a Pareto distribution, allowing them to write the solution formulae for the elasticity of unemployment duration with respect to the level of unemployment benefits $\left(\eta_{\theta, b}\right)$, and the elasticity of unemployment duration with respect to the rate of job offers $\left(\eta_{\theta, \lambda}\right)$ as: 


$$
\eta_{\theta, b}=\frac{\partial \log \theta}{\partial \log b}=-\frac{b}{\sigma \xi} \frac{x-\xi}{x-b}
$$

and

$$
\eta_{\theta, \lambda}=\frac{\partial \log \theta}{\partial \log \lambda}=1-\frac{\xi-b}{\sigma \xi} \frac{x-\xi}{x-b}
$$

where $o$ is the standard deviation of $(\log )$ wage offers. ${ }^{1}$ Note that if an individual moves through time with constant hazard $\theta$, then his or her completed unemployment duration is exponentially distributed with mean unemployment duration equal to $1 / \theta$. The benefit and offer probability elasticities of mean duration are now the negative of (3) and (4), and it is these transformed values that will be reported below.

Lancaster and Chesher provide elasticities for Britain in the 1970s. We provide updated estimates for Britain in the 1990s and for most other European Union (EU) nations as well (viz. Germany, Denmark, the Netherlands, Belgium France, Ireland, Italy, Greece, Spain, Portugal and Austria).

\section{Data}

Our data are taken from six waves of the European Community Household Panel (ECHP), 1994-99, covering all the (then) 15 nations in the European Union (but see below). ${ }^{2}$ As we have seen, calculating our key elasticities requires information on three variables. Beginning with reservation wages, the ECHP asks of those individuals actively looking for work first "Assuming you could find suitable work, how many hours per week would you prefer to work in this new job?" and, second, "What is the minimal net monthly income would you accept to work [number of hours in previous question] hours a week in this new job?" The reservation wage measure used here is an hourly net reservation wage construct, and along with all other variables is deflated by the relevant national consumer price index. We need add that for Germany reservation wage data is available for just the first three waves of the panel.

The data on unemployment benefits contained in the ECHP is with one exception a monthly measure. It is comparable to the Lancaster-Chesher measure of unemployment income but, as is the case for all our variables, is provided in continuous rather than 
categorical form. Monthly benefit entitlements are not provided for Finland, which country is therefore excluded.

Unlike the dataset(s) used by Lancaster and Chesher, the ECHP does not contain information on expected wages; rather, the closest information we have is the monthly remployment wage subsequently received. This is used to form an expected hourly wage measure for the sample, which is further reduced by two countries - Sweden and Luxembourg - where the data do not allow us to unemployed individuals through time. We do not here adjust our counterpart of the 'expected wage' for selection in to reemployment, although we have elsewhere reported on applying this procedure (see Addison, Centeno, and Portugal, 2004.) Note also that the reported number of hours worked per month in the reemployment job can diverge from the individual's optimal number of hours reported in the reservation wage question. In these circumstances, we used the latter to construct the expected hourly wage measure.

Finally, theory requires that that no individual has a reservation wage less than his or her level of unemployment benefit entitlement. Further, reservation wages should not exceed expected wages. We investigate the effect of imposing these two sets of restictions on the data. The effect of the former is to reduce the sample by 10 percent, while the latter results in a larger reduction in sample size of approximately 46 percent.

\section{Findings}

Computed elasticities are contained in Table 1. Panel (a) of the table gives results for the unrestricted sample. Note the instances of perversely signed estimates for three out of four elasticites: for the benefit elasticity of reservation wages in the cases of Belgium, and Greece; for the offer probability elasticity of reservation wages for the Netherlands, the U.K., and again Belgium and Greece; and for the offer probability elasticity of unemployment duration in the cases of Belgium and Greece. Observe that the net effect of an increase in the probability of an offer on duration is (generally) negative, meaning that its effect on the asking price outweighs the effect of more offers.

(Table 1 near here) 
Imposing the restriction that reservation wages exceed benefit levels in panel (b) results in the loss of roughly one-tenth of the sample. The main finding is that instances of perversely signed elasticities are now confined to the Belgian and Greek data alone. The estimates obtained for the U.K. are in absolute terms in each case below those calculated by Lancaster and Chesher $\left(\eta_{\xi, b}=0.135 ; \eta_{\xi, \lambda}=0.107 ;-\eta_{\theta, b}=1.03\right.$; and $-\eta_{\theta, \lambda}=$ -0.190).

A much larger loss in sample size of around 46 percent is occasioned when in panel (c) we impose the restriction that accepted wages cannot lie below reservation wages, and we lose Germany where all individuals in this attenuated sample violate the restriction. Not surprisingly, the effect of imposing this second theoretical restriction is significant: the estimated elasticities typically increase in magnitude and there are no longer any errant signs. In the case of the U.K. it is apparent that our estimates are now very much closer to those calculated by Lancaster and Chesher. Furthermore, these figures are, in general, considerably larger than those summarized in Cahuc and Zylberberg (2004, pp.157-58).

Finally, there is one obvious pattern in the data shown in panel (c) of the table that we mention without further comment. Countries with higher benefit elasticities of reservation wages have higher benefit elasticities of unemployment duration $\left(\hat{\eta}_{\theta, b}=0.061+0.106 \hat{\eta}_{\xi, b} ; \quad R^{2}=0.576\right)^{3}$

\section{Conclusion}

In an important paper, Lancaster and Chesher (1983) used survey data on unemployed persons in Britain and economic theory to deduce - rather than estimate via a formal statistical model - the structural parameters of the optimal search model. We follow their methodology to derive updated elasticities for Britain and for ten other European nations as well. Our findings are numerically consistent with the theory once two critical restrictions are imposed on the international data. 


\section{Endnotes}

1. The $\sigma$ parameter is obtained from $\sigma=\frac{x-\xi}{x}$.

2. For a description of this unique dataset, see for example, EUROSTAT (1999).

3. On the maintained hypothesis that countries with more flexible labor markets might well have larger elasticities, we regressed the four measures in panel (c) on OECD indicators of the country's unemployment benefit replacement rate and the stringency of its employment protection regime. The results were uniformly statistically insignificant. Indeed, the only strong external empirical regularity we detected was the unsurprising strongly positive correlation between the benefit elasticity of unemployment duration and the unemployment rate.

\section{References}

Addison, J.T., Portugal, P., Centeno, M., 2004. Reservation wages, search duration, and accepted wages in Europe. IZA Discussion Paper No. 1252. Bonn: IZA.

Cahuc, P., Zylberberg, A. 2004. Labor Economics, MIT Press, Cambridge, MA.

EUROSTAT, 1999. European Community Household Panel. Longitudinal Users' Database. Waves 1, 2 and 3. Manual. Luxembourg: EUROSTAT.

Lancaster, T., Chesher, A., 1983. An econometric analysis of reservation wages. Econometrica 51, 1661-1676. 


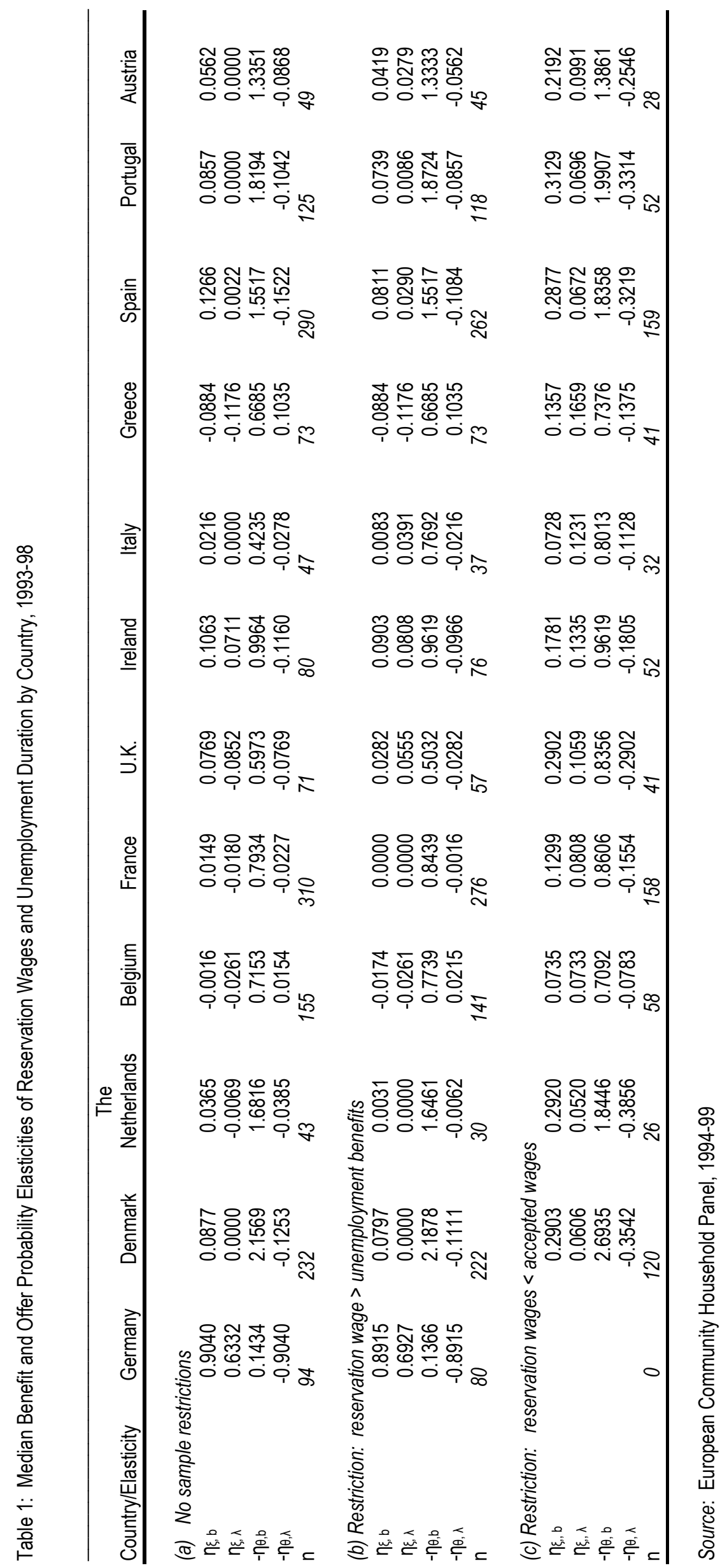

